\title{
SIMULATION OF THE GEOTHERMAL RESERVOIR OF THERMA - NIGRITA, CENTRAL MACEDONIA, GREECE
}

\author{
Kavouri K. ${ }^{1}$, Arvanitis A. ${ }^{1}$, Athanassoulis C. $^{1}$ and Xenakis M. ${ }^{1}$ \\ ${ }^{1}$ Institute of Geology and Mineral Exploration, $1^{\text {st }}$ Spirou Louis St., Olympic Village, 13677, \\ Acharnae, Greece, k.kavouri@igme.gr
}

\begin{abstract}
The geothermal field of Therma - Nigrita is among the most important low enthalpy fields in Greece. It is located at the SW part of the Strymon basin (Central Macedonia). The geothermal research at Nigrita was launched by IGME during 19801982. Actually, it is exploited mainly for agricultural use and thermal spa. The geothermal field of Therma - Nigrita, officially characterized by Ministerial Decision, covers an area of $10 \mathrm{~km}^{2}$, has a pressurized reservoir at 70-500 m depth, showing temperatures of $40-64^{\circ} \mathrm{C}$ and geothermal fluids containing large amounts of $\mathrm{CO}_{2}$. In this paper the development of a $3 D$ model for the reservoir of Therma - Nigrita, is presented. For this purpose the FEFLOW code is employed which simulates fluid flow and heat transfer in the geothermal reservoir under transient state conditions. Following, three different management scenarios are tested for a ten-year period. The first scenario examines the evolution of the reservoir under no-exploitation conditions, the second one represents the current exploitation scheme and in the third scenario the production rates are doubled. According to the simulation results, the decrease in temperature is not expected greater than $1 \%$ for all scenarios, while the effect on hydraulic heads is significant for both scenarios 2 and 3.
\end{abstract}

Keywords: 3D modelling, low enthalpy, geothermal filed management, FEFLOW.

\section{Пєрí $\eta \psi \eta$}

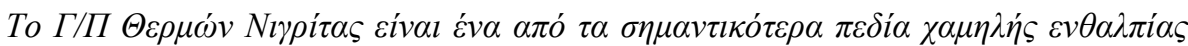

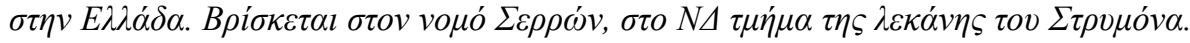

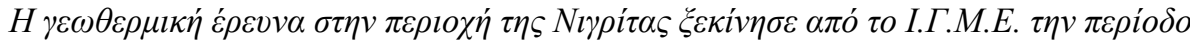

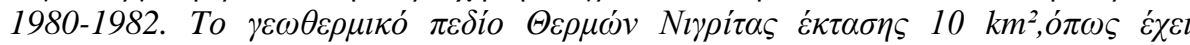

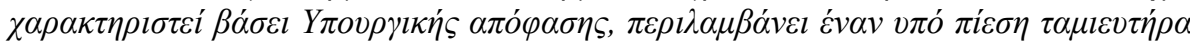

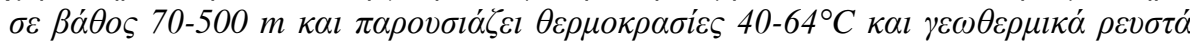

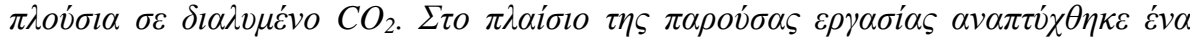

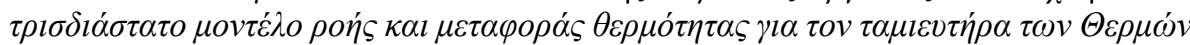

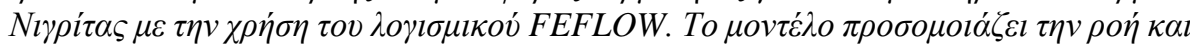

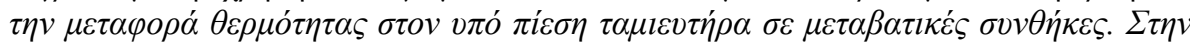

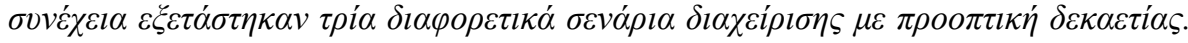

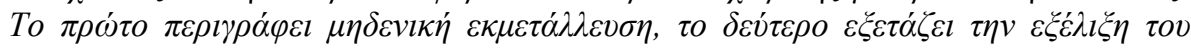

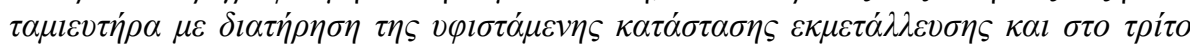

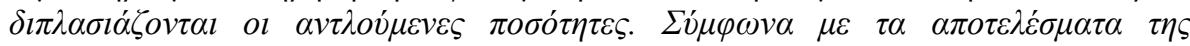

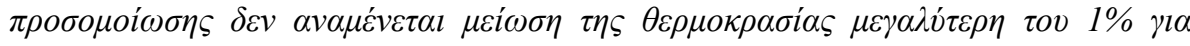

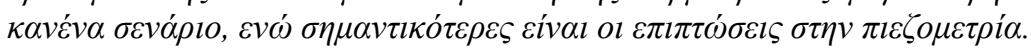

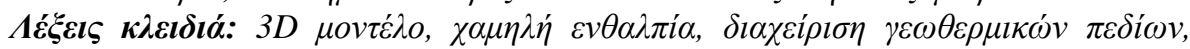
FEFLOW. 


\section{Introduction}

Over the last years the interest in low-enthalpy geothermal resources, for both electric and thermal energy production, is increasing globally. Yet, the current level of use of geothermal energy in Greece represents only a very small fraction of the identified geothermal resources (Andritsos et al., 2007). According to Goldstein et al. (2011), one of the greatest obstacles to the expansion of geothermal energy development is the inability to predict geothermal reservoir performance.

Several investigative approaches are employed for the characterization of geothermal resources, including field experimentation, numerical simulation, geochemical and isotopic characterization and other (Dotsika, 1991; Lopez et al., 2010; Bridger and Allen, 2014).

Numerical modelling provides a powerful tool to estimate the principal hydraulic and thermal parameters of a geothermal field and allows for a more accurate assessment of geothermal resources. Furthermore, the employment of distributed parameter models allows for the integration of spatial heterogeneities.

In this paper the development of a 3D model for the reservoir of Therma - Nigrita, is presented. The present study constitutes the first modelling attempt for this field. For this purpose the FEFLOW code (Diersch, 2014) is employed, which simulates fluid flow and heat transfer in the geothermal reservoir under transient state conditions.

Following, three different management scenarios are tested for a ten-year period. The first scenario examines the evolution of the reservoir under no-exploitation conditions, the second one represents the current exploitation scheme and in the third scenario the production rates are doubled.

The principal objective of the present study is to assess the principal characteristics of the geothermal reservoir and to estimate the potential of the geothermal field under study, via numerical modelling.

\section{General characteristics of the Therma - Nigrita geothermal field}

The geothermal field of Therma - Nigrita is located in the Region of Central Macedonia, Greece. It covers an area of $10 \mathrm{~km}^{2}$ and it is part of the Strymon basin, a region of great geothermal interest (Karydakis et al., 2005).

The geothermal research at Nigrita was launched by IGME during 1980-1982 with the drilling of five (5) exploratory wells (TH-1 to TH-5) at Therma (Karydakis, 1983) and continued during 19971999 with the drilling of seven (7) more productive wells (TH-6 to TH-12) (Karydakis, 2001). In the wider area there are also numerous private wells (PRIV-1, PRIV-2, N-15, N-16, TH-DB1 and other). The hot springs of Therma - Nigrita, located $3 \mathrm{~km} \mathrm{~S}$ and SE of the town of Nigrita, are currently dry.

The geological background of the area consists of metamorphic rocks of the Serbomacedonian mass and thick sedimentary deposits of Neogene age. For the most part the Neogene deposits are rich in clay and marl components, and present poor hydraulic characteristics.

The aquifer body consists of a basal conglomerate formation which develops at the depth of 70 to $500 \mathrm{~m}$. The reservoir presents pressurized heads, and measured temperatures range from 40 to $64^{\circ} \mathrm{C}$. According to Arvanitis et al. (1998), the total potential of the field is estimated to $1,000 \mathrm{~m}^{3} / \mathrm{h}$. The field is exploited mainly for agricultural use and thermal spa.

In respect to their chemical characteristics, the geothermal fluids are of $\mathrm{Na}-\mathrm{HCO}_{3}$ type and contain large amounts of $\mathrm{CO}_{2}$ (Arvanitis et al., 1998). The $\mathrm{pH}$ and TDS values range from 5.8-7.2 and 1.5$2.5 \mathrm{~g} / \mathrm{l}$ respectively.

The tectonic structure of the area is affected by two groups of normal faults (NW-SE and NE-SW direction) that control the movement of the geothermal fluids in the area. The intersection of the two fault systems is likely the main path for the upward migration of geothermal fluids originating from 
deeper layers. The geothermal fluid is then diffused into younger and permeable sediments, such as the basal conglomerate formation (Arvanitis et al., 1998).

The spatial distribution of isothermal curves follows the directions of the main fault systems. The area presenting highest temperatures is located near the productive wells TH-12 and TH-DB1 (Figure 1).

Similarly, the distribution of pressure in the geothermal reservoir indicates that the recharge zone is located in the northeast part of the field (close to TH-12 and TH-DB1) where the greatest pressure gradient reveals. West and southwest of this area, the pressure gradient is lower and the water is colder.

A simplified map of the geothermal field is presented in Figure 1 and the conceptual model of the geothermal reservoir is presented in Figure 2.

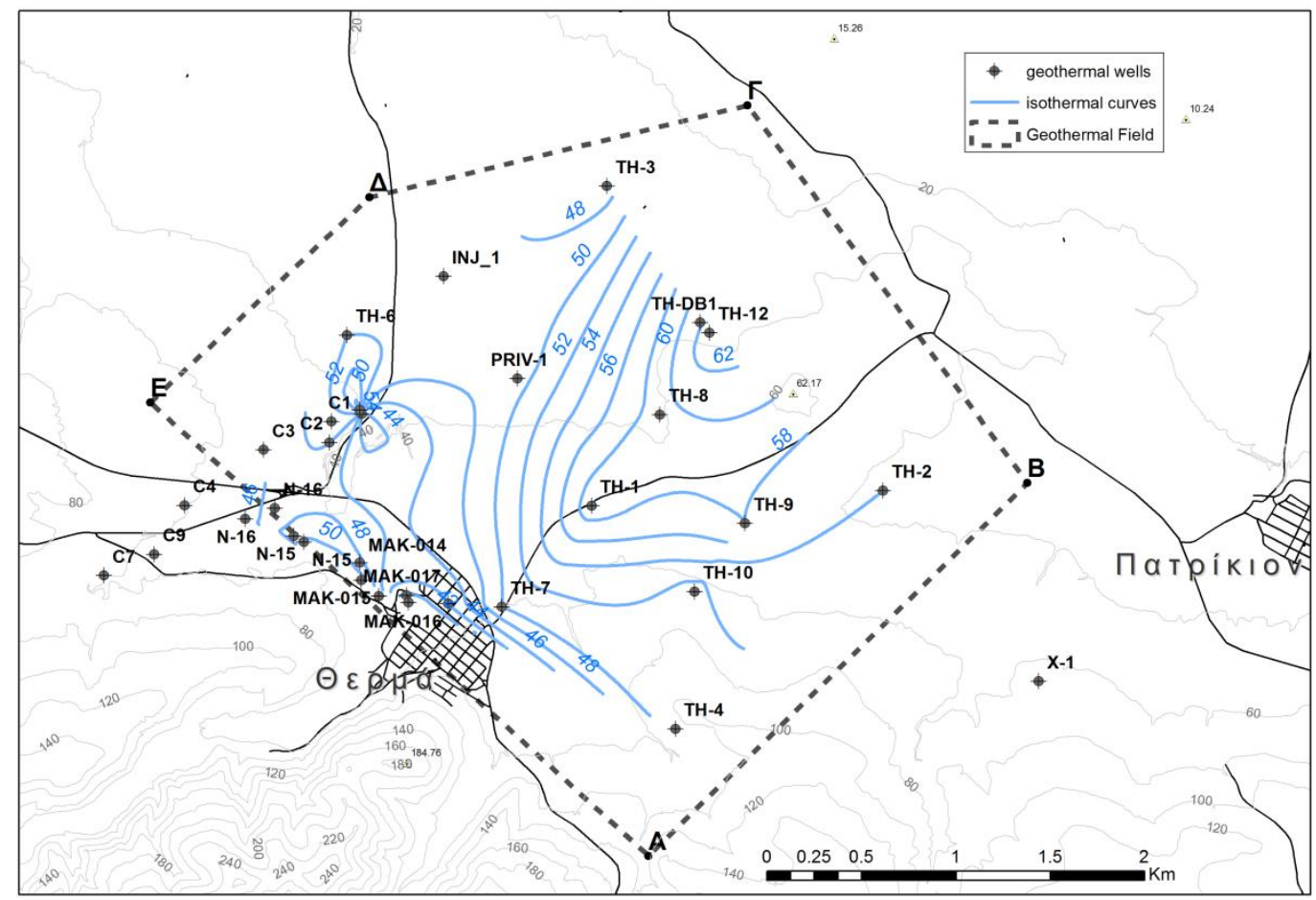

Figure 1 - The geothermal field of Therma - Nigrita. 


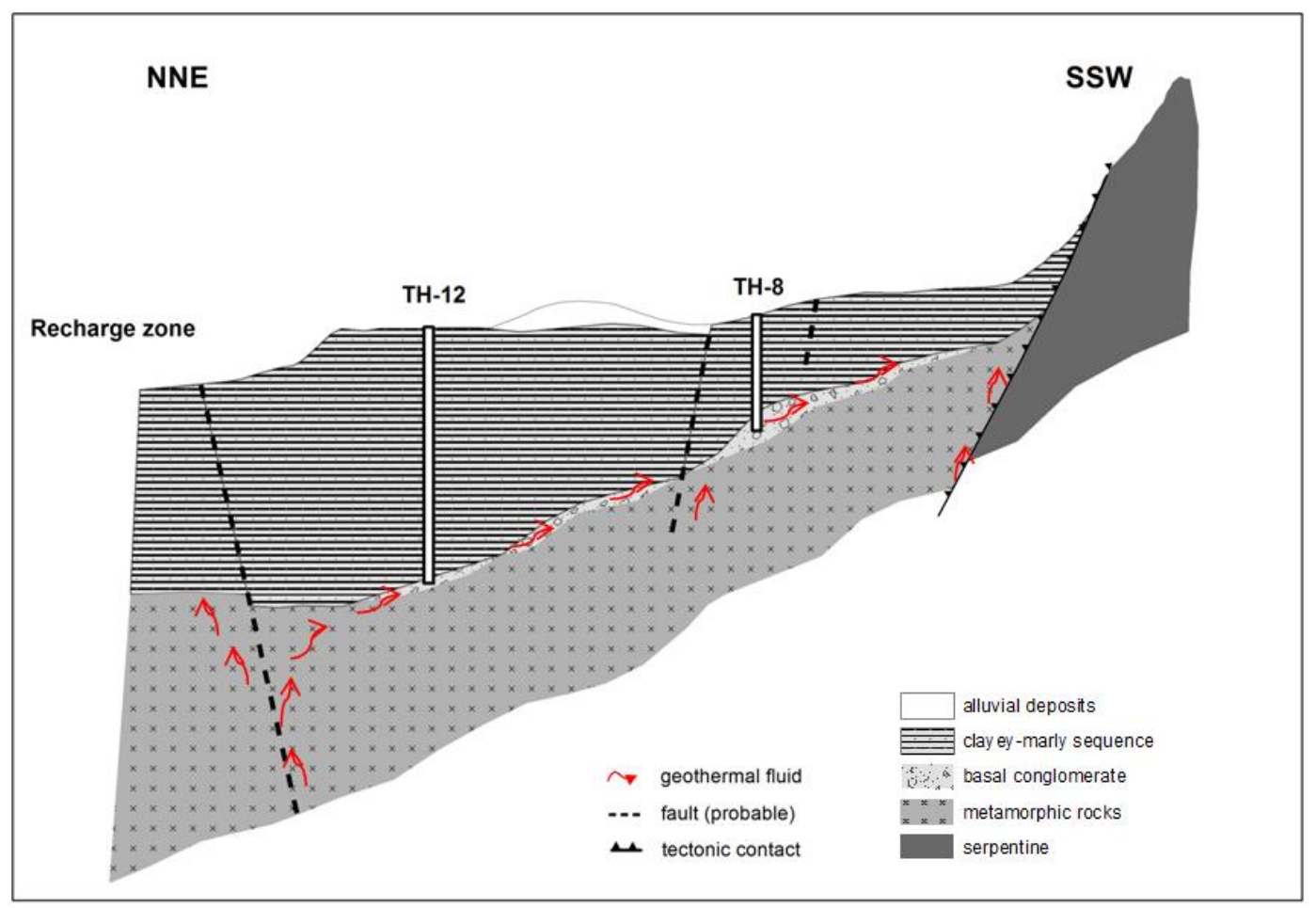

Figure 2 - Schematic cross section - conceptual model of the geothermal field Therma Nigrita.

\section{Development of the 3D model}

The model is developed for transient state conditions. The employed observation wells are TH-1, TH-8, PRIV-1 and PRIV-2 (Figure 1). Periodic measurements of temperature are realized by IGME at the framework of Diachronic Monitoring of Geothermal Fields of Greece (NSRF 2007-2013 project).

\subsection{Structural characteristics of the model}

The model is developed with the FEFLOW finite element simulator, using a layered three dimension technique. The model consists of 172.536 prismatic elements and 115.984 nodes. It comprises two layers, each one representing a different hydro-geological unit. The top layer stands for the quasiimpermeable clayey-marly sequence, which is the restrictive cover of the reservoir, while the bottom layer represents the basal conglomerate formation which is the main aquifer body.

The absolute elevation of the top and bottom slice of each layer is based on the spatial analysis of geological data from 21 boreholes distributed at the wider area of Nigrita. The geological formations are grouped into three hydro-geological units: i) the clayey-marly sequence, ii) the basal conglomerate and iii) the metamorphic basement.

The resulting geometry of the geothermal field is presented in Figure 3. 


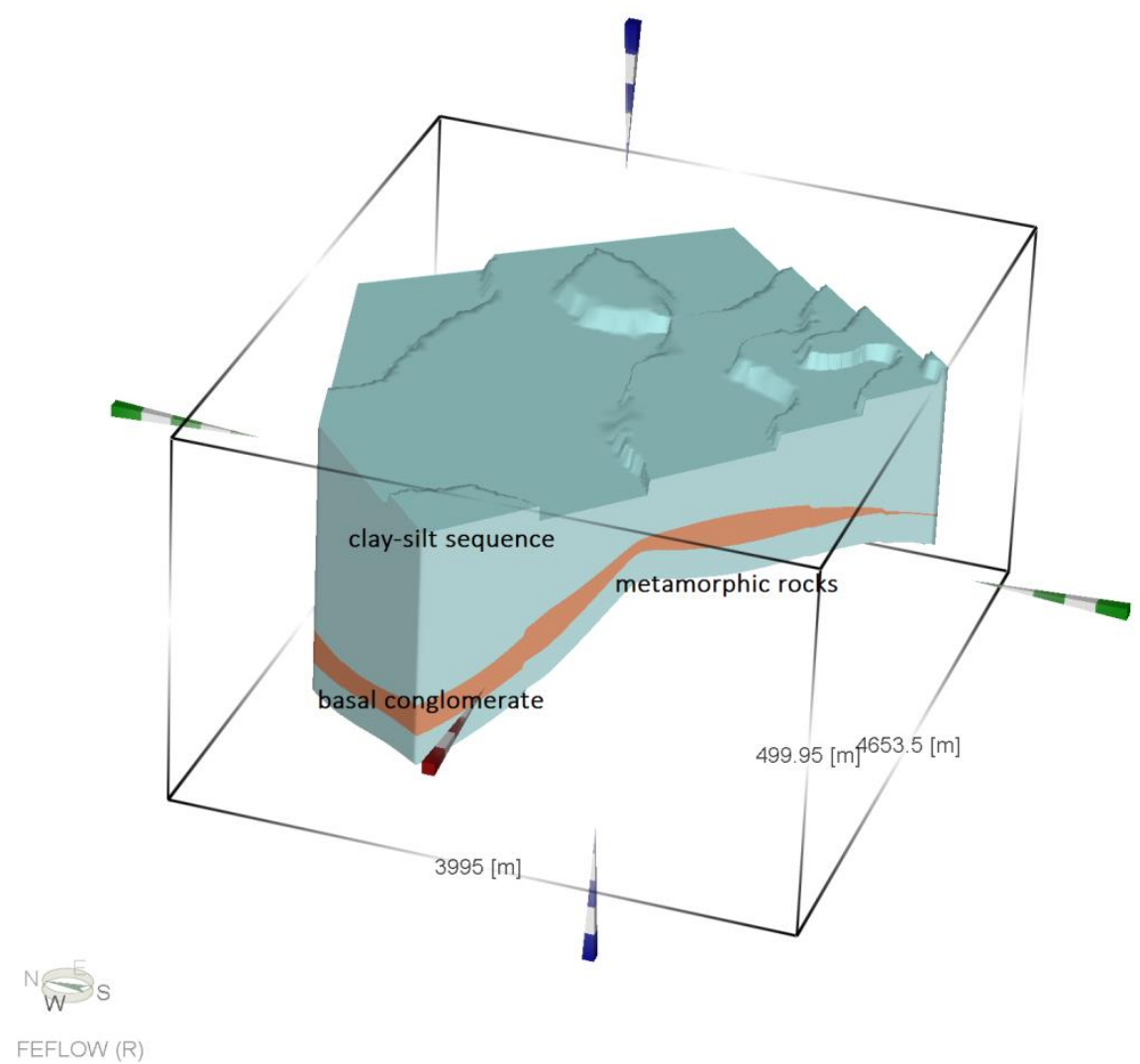

Figure 3 - Geometry of the geothermal field of Therma - Nigrita. The aquifer body is presented in red colour.

\subsection{Hydraulic and thermal properties}

In order to understand the mode of operation and to estimate the potential of the geothermal system, a thorough determination of the system hydraulic and thermal parameters is necessary.

In geothermal reservoir modelling the hydraulic conductivity determines fluid flow and heat transport conditions. The hydraulic conductivity of the upper clayey-marly sequence describes a practically impermeable formation. The lower layer, which simulates the basal conglomerate, is assigned with higher hydraulic conductivities. Furthermore, the lower layer is separated into two zones according to whether dissolved gas $\left(\mathrm{CO}_{2}\right)$ is present in the geothermal fluid. This distinction is used to simulate two regions of the same geological formation, which show different hydraulic characteristics due to the difference in composition and density of the geothermal fluid. The assigned values of hydraulic conductivity and storativity are shown in Table 1. Additionally, the anisotropy of hydraulic characteristics in the $\mathrm{z}$-axis is assigned 1/10.

Thermal properties describe the potential of heat to be transferred through the solid or to be stored into the rock material. The values of thermal conductivity and volumetric heat capacity of fluid and solid are assigned separately in the model (Table 1). 
Table 1 - Values of hydraulic and thermal properties of the model.

\begin{tabular}{|c|c|c|c|}
\hline Parameter & Hydrogeological formation & Value & Unit \\
\hline \multirow{3}{*}{ Hydraulic conductivity } & Clayey-marly sequence & $10^{-11}$ & $\mathrm{~m} / \mathrm{s}$ \\
\hline & Basal conglomerate & $6.510^{-4}$ & $\mathrm{~m} / \mathrm{s}$ \\
\hline & Basal conglomerate $\left(\mathrm{CO}_{2}\right)$ & $1.0610^{-4}$ & $\mathrm{~m} / \mathrm{s}$ \\
\hline \multirow[t]{3}{*}{ Storativity } & Clayey-marly sequence & 0.0001 & $1 / \mathrm{m}$ \\
\hline & Basal conglomerate & 0.0002 & $1 / \mathrm{m}$ \\
\hline & Basal conglomerate $\left(\mathrm{CO}_{2}\right)$ & 0.0002 & $1 / \mathrm{m}$ \\
\hline \multirow[t]{2}{*}{ Porosity } & Clayey-marly sequence & 0.001 & \\
\hline & Basal conglomerate & 0.3 & \\
\hline \multirow[t]{2}{*}{ Thermal conductivity of solid } & Clayey-marly sequence & 2.4 & $\mathrm{~J} / \mathrm{m} / \mathrm{s} / \mathrm{K}$ \\
\hline & Basal conglomerate & 4.2 & $\mathrm{~J} / \mathrm{m} / \mathrm{s} / \mathrm{K}$ \\
\hline Thermal conductivity of fluid & Fluid & 0.65 & $\mathrm{~J} / \mathrm{m} / \mathrm{s} / \mathrm{K}$ \\
\hline \multirow{2}{*}{ Volumetric heat capacity of solid } & Clayey-marly sequence & 2.64 & $\mathrm{MJ} / \mathrm{m}^{2} / \mathrm{K}$ \\
\hline & Basal conglomerate & 2.5 & $\mathrm{MJ} / \mathrm{m}^{2} / \mathrm{K}$ \\
\hline Volumetric heat capacity of fluid & Fluid & 4.2 & $\mathrm{MJ} / \mathrm{m}^{2} / \mathrm{K}$ \\
\hline
\end{tabular}

\subsection{Initial and boundary conditions (BC)}

The initial heads introduced to the model reproduce the pressure heads of all geothermal wells as measured during drilling. The same method is followed for the field of temperatures.

First type BCs are assigned punctually, based on field measurements realized at the well TH-7. Second type BCs (influx) are assigned at the northern border of the domain and pumping rates are assigned at the wells TH-8, TH-10, TH-11, PRIV-1 and PRIV-2.

The recharge at depth is a special boundary condition that controls how much fluid and heat is available and its distribution across the system. In the present study the recharge of the reservoir is assessed with the in/out flow on top/bottom module of FEFLOW at the bottom layer of the model. The delimitation of the recharge zone corresponds to the area of the reservoir where the highest temperatures are observed. The value of influx for the specific boundary condition is identified during the calibration of the model. Note that no recharge via precipitation is considered, as the reservoir is confined. Additionally, a constant temperature $\mathrm{BC}$ of $64^{\circ} \mathrm{C}$ is assigned at the recharge zone at the bottom layer.

\subsection{Calibration}

The calibration of the model is realized for the period 2005-2008. For the evaluation of the results the following error indicators are used: i) absolute error ( $\overline{\mathrm{E}})$, ii) root mean square error (RMS), and iii) standard deviation (SD). The results of the calibration for the parameter of temperature are presented in Figure 4. 


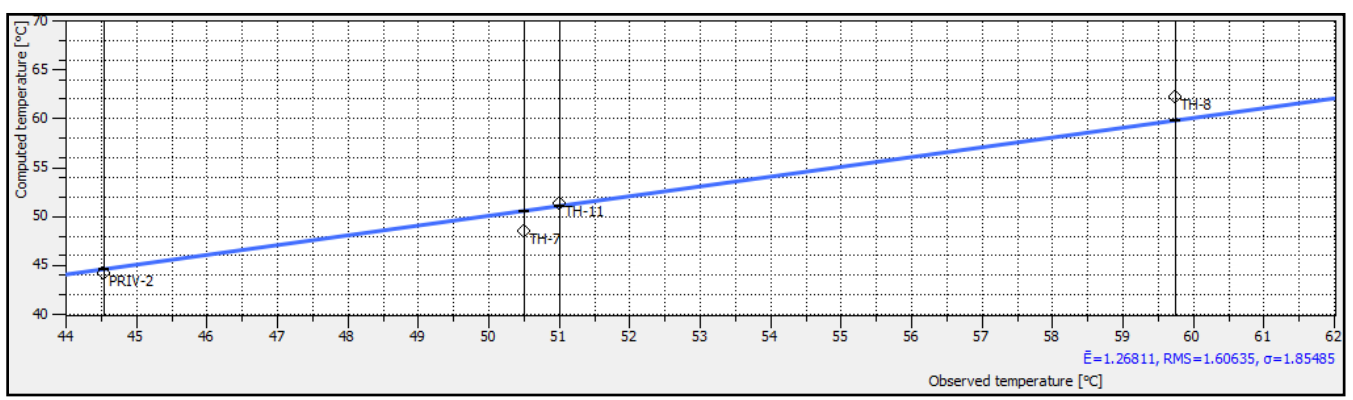

Figure 4 - Observed and simulated values of temperature at observation wells (TH-7, TH-8, TH-11 and PRIV-2).

\subsection{Sensitivity analysis}

In the present study a sensitivity analysis of hydraulic conductivity is performed by changing the value of the parameter by $\pm 5 \%$ and $\pm 10 \%$. For the evaluation of the results the same error indicators as in calibration ( $\overline{\mathrm{E}}, \mathrm{RMS}$ and SD) are used. The test results are shown in Table 2.

Table 2 - Comparative results of sensitivity analysis of hydraulic conductivity.

\begin{tabular}{|l|c|c|c|l|l|}
\hline & $\mathbf{0}$ & $\mathbf{- 5 \%}$ & $\mathbf{- 1 0 \%}$ & $\mathbf{+ 5 \%}$ & \multicolumn{1}{|c|}{$\%$} \\
\hline$\overline{\mathrm{E}}$ & 1.70864 & 1.71214 & 1.71249 & 1.71331 & 1.71738 \\
\hline $\mathrm{RMS}$ & 2.03774 & 2.04837 & 2.03928 & 2.0424 & 2.04654 \\
\hline $\mathrm{SD}$ & 2.27827 & 2.29015 & 2.27763 & 2.28347 & 2.2881 \\
\hline
\end{tabular}

It is observed that differences in error rates are very low. This indicates a low sensitivity of the model to this parameter.

\subsection{Management scenarios}

For the geothermal field of Therma - Nigrita three different management scenarios are designed having as prospect a decade. These scenarios are described below.

- - Scenario 1 (SC1) - No exploitation

The first scenario examines the evolution of the reservoir under steady state conditions. The results of this scenario will be used as background values in the comparison with other scenarios.

- - Scenario 2 (SC2) - Maintaining the current exploitation scheme

The second scenario examines the evolution of the reservoir in a period of ten years, if the current exploitation scheme is maintained.

- - Scenario 3 (SC3) - Increment of production rate by $100 \%$

Finally, the third scenario examines the evolution of the reservoir in a period of ten years, after doubling the production rates of geothermal fluid. This scenario is particularly interesting as it represents a realistic version of future management.

\section{Results and discussion}

The simulation of the geothermal reservoir of Therma - Nigrita is realized for the period 2005-2008. The distribution of temperature at the end of the simulation period is presented in Figures 5 and 6. 


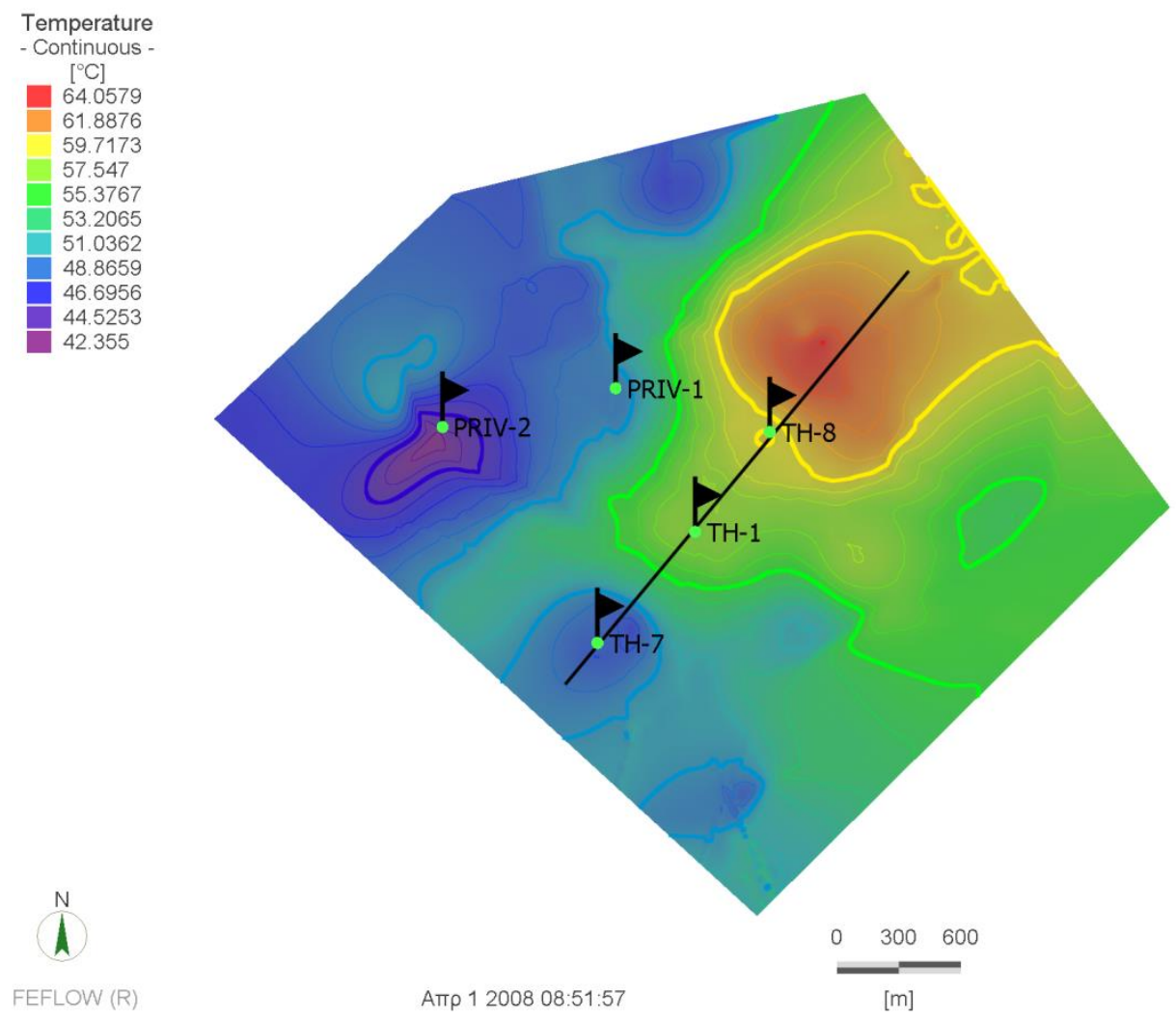

Figure 5 - Simulated field of the reservoir temperature (layer 2). The location of the cross section is marked with black line.
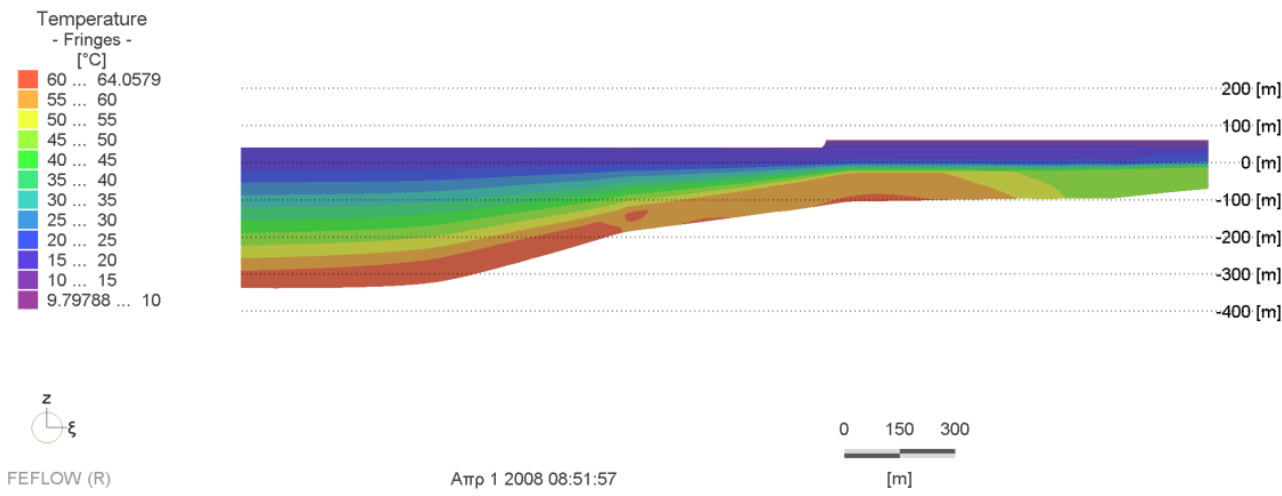

Figure 6 - Simulated field of temperature. Cross-section NE-SW.

The developed numerical model is employed for the assessment of the basic characteristics of the geothermal field based on the finite element method. Consequently, the reservoir volume is estimated $1.410^{+7} \mathrm{~m}^{3}$, of which $4.3810^{+6} \mathrm{~m}^{3}$ correspond to fluid volume. In steady state conditions the heat energy stored in fluid phase is estimated $29 \mathrm{TJ}$ and the total (fluid and solid) stored heat energy 69 TJ.

In respect to the examined scenarios the simulated values of hydraulic head and temperature are presented in Table 3. 
Table 3 - Comparative results of sensitivity analysis of hydraulic conductivity.

\begin{tabular}{|l|l|l|l|l|l|}
\hline \multicolumn{6}{|c|}{ Hydraulic head (m) } \\
\hline Well & TH-1 & TH-8 & PRIV-1 & PRIV-2 & TH-5 \\
\hline Scenario 1 & 49.96 & 55.89 & 53.05 & 45.82 & 45.96 \\
\hline Scenario 2 & 49.64 & 52.34 & 52.59 & 26.75 & 42.87 \\
\% variation & $0.64 \%$ & $6.35 \%$ & $0.87 \%$ & $41.62 \%$ & $6.72 \%$ \\
\hline Scenario 3 & 49.32 & 48.79 & 52.12 & 7.67 & 39.78 \\
\% variation & $1.28 \%$ & $12.70 \%$ & $1.75 \%$ & $83.26 \%$ & $13.45 \%$ \\
\hline \multicolumn{7}{|c|}{ Temperature ( $\left.{ }^{\circ} \mathbf{C}\right)$} \\
\hline Scenario 1 & 55.23 & 45.31 & 52.63 & 48.5 & 55.23 \\
\hline Scenario 2 & 55.13 & 45.19 & 52.62 & 48.83 & 55.13 \\
\% variation & $0.17 \%$ & $0.25 \%$ & $0.02 \%$ & $0.68 \%$ & $0.17 \%$ \\
\hline Scenario 3 & 55.06 & 45.05 & 52.60 & 48.94 & 55.06 \\
\% variation & $0.29 \%$ & $0.57 \%$ & $0.05 \%$ & $0.91 \%$ & $0.29 \%$ \\
\hline
\end{tabular}

As expected for the first scenario there are no changes in the examined parameters. This scenario is not a realistic management scenario, as no exploitation takes place in the geothermal field. The results of the first scenario are used as reference to evaluate the variations of the parameters in scenarios 2 and 3 .

In the second scenario no important modifications in hydraulic heads are observed at the wells $\mathrm{TH}$ 1 and PRIV-1. The hydraulic heads are reduced by 6-7\% at the wells TH-8 and TH-5, and 41.62\% at the well PRIV-2. Changes in temperature do not exceed $1 \%$.

In the third scenario changes in hydraulic heads for the wells TH-1 and PRIV-1 range between 1$2 \%$. The hydraulic heads are lowered by $12-14 \%$ at the wells TH- 8 and TH-5, while a decrease of $83.26 \%$ is observed in the hydraulic head of the well PRIV-2. Again, changes in temperature do not exceed $1 \%$.

The results of the scenarios indicate the existence of an important source of heat, which is not expected to diminish with the current exploitation scheme, or if the exploitation rates are doubled. In contrast, the fluid volumes are strongly influenced by pumping, especially at wells located far from the recharge zone.

A sustainable management scheme for the geothermal field of Therma - Nigrita should include reinjection of the extracted fluids in the reservoir. This way the water balance is maintained, but also the recovery of thermal energy can be maximized.

\section{Acknowledgments}

The present study was funded by the National Strategic Reference Framework (NSRF 2007-2013 / code 350913).

\section{References}

Andritsos, N., Dalabakis, P., Karydakis, G., Kolios, N. and Fytikas, M., 2007. Update and Characteristics of Low-Enthalpy Geothermal Applications in Greece, Proc. of the European Geothermal Congress 2007, Unterhaching, Germany.

Arvanitis, A., Fytikas, M. and Dotsika, E., 1998. Geothermal conditions in Therma - Nigrita area (Strymon basin, Northern Greece), Bull. Geol. Soc. Greece, XXXII/4, 229-242. 
Bridger, D.W. and Allen, D.M., 2014. Influence of geologic layering on heat transport and storage in an aquifer thermal energy storage system, Hydrogeology Journal, 22, 233-250.

Diersch, H.-J., 2014. FEFLOW. Finite Element Modeling of Flow, Mass and Heat Transport in Porous and Fractured Media. Springer 2014 Springer-Verlag Berlin Heidelberg.

Dotsika, E., 1991. Utilisation du geothermometre isotopique sulfate-eau en milieux de haute temperature sous influence marine potentielle: les systemes geothermaux de Grece, These en Science, Univ. Paris-Sud, 184 pp.

Goldstein, B., Hiriart, G. and Tester, J., 2011. Great expectations for geothermal energy to 2100: messages for now, GRCTrans, 35, 1175-1183

Karydakis, G., 1983. Study of the low enthalpy geothermal field in Therma - Nigrita area. Report I.G.M.E., Athens, 46 pp.

Karydakis G., 2001. Geothermal exploration at the area Therma - Nigrita, Report I.G.M.E., Athens, $24 \mathrm{pp}$.

Karydakis, G., Arvanitis, A., Andritsos, N. and Fytikas, M., 2005. Low Enthalpy Geothermal Fields in the Strymon basin (Northern Greece), Proc. of the World Geothermal Congress 2005, Antalya, Turkey, 24-29 April, IGA \& TGA, Paper Number 2615, 12 pp.

Lopez, S., Hamm, V. and LeBrun, M., 2010. 40years of Dogger aquifer management in Ile-deFrance, Paris Basin, France, Geothermics, 39, 339-356. 